\title{
A Study on Quality of Life and Self Esteem in children and adolescents with Strabismus
}

\author{
Heena Merchant ${ }^{1}$, Tanmay Murur ${ }^{2}$, Avinash De Sousa ${ }^{3}$, Shruti Shirwadkar ${ }^{4}$, Nilesh Shah ${ }^{5}$, \\ Sagar Karia ${ }^{6}$, Chhaya Shinde ${ }^{7}$
}

${ }^{1}$ Associate Professor, Department of Psychiatry,

${ }^{2} 3$ rd year Medical Student (III/I),

${ }^{3}$ Research Associate, Department of Psychiatry,

${ }^{4}$ Assistant Professor, Department of Ophthalmology,

${ }^{5}$ Professor and Head, Department of Psychiatry,

${ }^{6}$ Assistant Professor, Department of Psychiatry,

${ }^{7}$ Professor and Head, Department of Ophthalmology,

Lokmanya Tilak Municipal Medical College and General Hospital, Mumbai.

Corresponding author: Avinash De Sousa

Email-avinashdes888@gmail.com

\begin{abstract}
Background/Context: Strabismus is a condition that results in loss of self esteem and affects quality of life due to the changes it may cause in facial appearance and other factors. There is a dearth of Indian literature on children and adolescents with strabismus. The current study analyzed self esteem and quality of life in children and adolescents with strabismus.

Methods: Children and adolescents between 6-17 years attending the ophthalmology out-patient department of a tertiary general hospital and their normal siblings were identified and assessed after parental consent using a semi-structured proforma and the KINDL questionnaire. The results were statistically analyzed and presented.

Results: 35 children and adolescents with strabismus were compared to 38 siblings who were the controls. It was seen that children and adolescents with strabismus scored lower on family and social contacts quality of life scores on all subscales of the KINDL questionnaire. However, self-esteem did not differ across both groups.

Conclusion: Further larger studies in diverse populations are needed to corroborate the effects of strabismus on self esteem and quality of life.
\end{abstract}

Key words: self-esteem, strabismus, quality of life, children, adolescents.

(Paper received $-6^{\text {th }}$ August 2019, Peer review completed $-30^{\text {th }}$ September 2019)

(Accepted $-5^{\text {th }}$ October 2019)

\section{INTRODUCTION}

Strabismus is a condition associated with abnormal binocular vision that leads to ocular misalignment, blurring, eye strain and diplopia causing a change in the normal facial appearance of the individual [1]. Studies have demonstrated that patients with strabismus patients suffer from both psychological problems and social impairments [2]. There has been an increased incidence of psychological problems like anxiety and depression correlated with strabismus that may also affect the quality of life of the patient adversely [34]. Strabismus is commonly seen in India and the incidence varied from $0.13 \%-4.7 \%$ across various studies conducted [5]. The psychosocial implications of strabismus are relevant in school going children who might be bullied and ridiculed due to the changes in facial appearance as seen in exotropia or esotropia [6]. 
In a Turkish study, teachers were asked about their impression about photographs digitally altered to show children with orthotropia, esotropia and exotropia and their perceptions were noted. There was a significant social bias against children with strabismus, reported even by their teachers [7]. Children with strabismus may be treated differently by their peers and even by parents during caregiving and authority figures owing to the changes in their facial appearance [8]. Strabismus may thus cause low self- esteem in the child as eye contact is important for good communication skills and children with strabismus may face a problem this area during ordinary conversations with people and in specific social situations [9]. Studies have demonstrated that children with strabismus face issues like severe difficulty in communication, difficulty coping in social situations and immense social anxiety [10]. Thus, strabismus may affect the child's quality of life both due to psychosocial factors and appearance defects even when there is no significant diminution of vision or functional impairment [11-12]. Previous studies in children and adolescents with strabismus between the age of 3-17 years have reported poorer quality of life and low self-esteem in these groups [1314]. There is scarce literature on quality of life and self esteem in children with strabismus in India. The present study was thus aimed at studying quality of life and self esteem in children and adolescents with strabismus attending the outpatient department in a tertiary general hospital

\section{METHODOLOGY}

The study was a cross-sectional, single center study conducted in a tertiary general hospital in Mumbai. The study was conducted over a period of four months between June and September 2018. The study was conducted in children with strabismus attending the ophthalmology out patient department of the hospital. The parents of the children were explained the nature and purpose of the study and written informed valid consent from them was obtained. The children were also explained the nature and purpose of the study and where applicable assent for the study was obtained. The study cohort were patients between the age of 6-17 years having strabismus. Due to the limited time period of the study cases and controls were recruited on a first come first serve basis and no sample size calculation using power data was done.

Children and adolescents with severe cognitive or neuropsychiatric problems and major medical or surgical disorders that may cause impairments of self-esteem or quality of life were excluded from the study. Children and adolescents who have already had successful strabismus surgery were also excluded. The control group were siblings of these patients in the age range 6-18 years. respectively. Similar exclusion criteria were applied to the siblings as well. The control group chosen was chosen as siblings of the study group as most factors which affected self-esteem was assumed to be common to both groups and strabismus was probably a major differentiating factor between the two groups.

A semi-structured proforma for data collection of socio-demographic variables was constructed for the purpose of this study and administered. Data on self esteem and quality of life in both groups was collected using the KINDL Questionnaire.

The KINDL questionnaire is a standardized measure of quality of life and self-esteem in the age group of 318 years. It has good reliability and validity with Cronbach's alpha of 0.70 . It consists of 24 likert - scaled items associated with six dimensions viz. physical well-being (eg. during the past week I fell ill), emotional well-being (eg. During the past week I felt good about myself), family (during the past week I felt fine at home), friends (during the past week I got along well with my friends) and everyday functioning (school) (during the last week I enjoyed my lessons). The items in the scale give 5 responses from 'Never' to 'All the time'. The proxy version Kid/Kiddo KINDL parents for 6-17 years of age was used in this study.[15-16] The questionnaire was administered by a qualified psychiatrist (HM) who was also an author in the study.

Ethical clearance for the study was obtained from the Institutional Ethics Committee. The data was analyzed using SPSS statistical software version 17 and descriptive statistics for the ages like mean and standard deviation along with the unpaired $t$ test to compare scores on the scale were used. 


\section{RESULTS}

The study subjects were 35 children and adolescents having strabismus and 38 of their normal sibling that functioned as the control group. In the study group there were 20 females and 15 males having strabismus. In the control groups there were 21 females and 17 males. In the strabismus group, there were 24 (68.57\%) esotropes and 11 (31.43\%) exotropes. Headache, eyestrain and difficulty in reading were the common symptoms associated with squint seen in majority of the patients $(n=20,57.14 \%)$. The mean age of the study group was calculated to be $11.60 \pm 4.3$ years and that of the control group was $10.73 \pm 3.8$ years. No epidemiological data could be ascertained due to the sample size.

On assessing the study and control groups on the KINDL questionnaire, it was seen that children and adolescents with strabismus scored significantly lower on family and social contact scores of quality of life than the control group (Table 1). Physical and emotional well being subscale scores showed no differences between the group and surprisingly the two groups did not differ on self esteem scores. The self esteem scores were high indicating good self esteem in the strabismus and control groups.

Table 1 - Comparison between study and control groups

\begin{tabular}{|c|c|c|c|c|}
\hline $\begin{array}{c}\text { KINDL Questionnaire } \\
\text { Subscales }\end{array}$ & $\begin{array}{c}\text { Strabismus Group } \\
\mathbf{( n = 3 5 )} \\
\text { Mean } \pm \text { SD }\end{array}$ & $\begin{array}{c}\text { Control Group } \\
\mathbf{( n = 3 8 )} \\
\text { Mean } \pm \text { SD }\end{array}$ & t value & p value \\
\hline Physical Well Being & $74.10 \pm 17.75$ & $69.07 \pm 23.11$ & 1.036 & 0.3036 \\
\hline Emotional Well Being & $69.29 \pm 17.31$ & $75.33 \pm 15.34$ & 1.5804 & 0.1185 \\
\hline Family & $59.82 \pm 16.49$ & $70.06 \pm 14.39$ & 2.8324 & $0.0061^{*}$ \\
\hline Social Contacts & $52.32 \pm 12.69$ & $63.98 \pm 16.14$ & 3.4141 & $0.0012^{*}$ \\
\hline Self Esteem & $66.78 \pm 11.29$ & $65.29 \pm 13.61$ & 0.5067 & 0.6141 \\
\hline
\end{tabular}

All calculations done using the Unpaired $t$ test $\left({ }^{*}\right.$ significant $\left.\mathrm{p}<0.05\right)$

\section{DISCUSSION}

The study demonstrated that quality of life is significantly worse in strabismus. Many studies in past have shown results on similar lines [17-18]. These studies attribute this reduced quality of life to just not only the functional impairments caused by strabismus, but also due to psychosocial disturbances caused by bullying or cosmetic disfigurement caused by strabismus [18]. There have been studies that have demonstrated that strabismus surgery improves quality of life in children and adolescents irrespective of the functional impairment due to the cosmetic changes and improvement in facial features [19].

In our study Family and Social Contact aspect of the quality of life were significantly reduced in children and adolescents with strabismus. The child with strabismus often may face discrimination at school and/or home and this possibly leads to some form of psychosocial disturbance [20]. A study has shown that $84.17 \%$ of the parents used to feel that other people notice their child's strabismus during interaction, $91.67 \%$ parents considered strabismus as a form of facial disfigurement while $61.67 \%$ parents felt that their children would have difficulty in interacting with their own peer group and in making friends [21]. The two groups however did not differ on self-esteem scores. Parents filling in the questionnaires for both children may have had a bias that led to the same. The perception of self esteem is highly varied and this also may have affected the scores [22].

In this study decrease in quality of life could not be purely attributed to the strabismus and but there may have been multiple factors at play. The limitations of this study were a small sample size, a relatively short time period of 4 months and the cross-sectional nature of the study. Further larger studies in diverse samples are need to corroborate and give impetus to the findings of this study. 


\section{REFERENCES}

1. Castanes MS. Major review: The underutilization of vision screening (for amblyopia, optical anomalies and strabismus) among preschool age children. Binoc Vision Strabismus Quart 2003;18(4):217-32.

2. Menon V, Saha J, Tandon R, Mehta M, Khokhar S. Study of the psychosocial aspects of strabismus. J Pediatr Ophthal Strabis 2002;39(4):203-8.

3. Lin S, Congdon N, Yam JC, Huang Y, Qiu K, Ma D, Chen B, Li L, Zhang M. Alcohol use and positive screening results for depression and anxiety are highly prevalent among Chinese children with strabismus. Am J Ophthal 2014;157(4):894-900.

4. Mohney BG, McKenzie JA, Capo JA, Nusz KJ, Mrazek D, Diehl NN. Mental illness in young adults who had strabismus as children. Pediatrics 2008;122(5):1033-8.

5. Singh H. Pattern of ocular morbidity in school children in central India. Strabismus. 2011;63(2):8-30.

6. Horwood J, Waylen A, Herrick D, Williams C, Wolke D. Common visual defects and peer victimization in children. Investig Ophthal Visual Sci 2005;46(4):1177-81.

7. Caca I, Cingu AK, Sahin A, Ari S, Dursun ME, Dag U, Balsak S, Alakus F, Yavuz A, Palanci Y. Amblyopia and refractive errors among school-aged children with low socioeconomic status in southeastern Turkey. J Pediatr Ophthal Strabismus 2013;50(1):37-43.

8. Satterfield D, Keltner JL, Morrison TL. Psychosocial aspects of strabismus study. Arch Ophthalmol 1993;111(8):1100-5.

9. Uretmen O, Egrilmez S, Kose S, Pamukcu K, Akkin C, Palamar M. Negative social bias against children with strabismus. Acta Ophthal Scand 2003;81(2):138-42.

10. Chai Y, Shao Y, Lin S, Xiong KY, Chen WS, Li YY, Yi JL, Zhang L, Tan G, Tang J. Vision-related quality of life and emotional impact in children with strabismus: a prospective study. J Int Med Res 2009;37(4):110814.

11. Wen G, McKean-Cowdin R, Varma R, Tarczy-Hornoch K, Cotter SA, Borchert M, Azen S, Multi-ethnic Pediatric Eye Disease Study Group. General health-related quality of life in preschool children with strabismus or amblyopia. Ophthalmology 2011;118(3):574-80.

12. Hatt SR, Leske DA, Adams WE, Kirgis PA, Bradley EA, Holmes JM. Quality of life in intermittent exotropia: child and parent concerns. Arch Ophthalmol 2008;126(11):1525-9.

13. Yamada T, Hatt SR, Leske DA, Holmes JM. Health-related quality of life in parents of children with intermittent exotropia. J Am Assoc Pediatr Ophthal Strabismus 2011;15(2):135-9.

14. Carlton J, Kaltenthaler E. Health-related quality of life measures (HRQoL) in patients with amblyopia and strabismus: a systematic review. Br J Ophthalmology 2011;95(3):325-30.

15. Bullinger M, Brütt AL, Erhart M, Ravens-Sieberer U, BELLA Study Group. Psychometric properties of the KINDL-R questionnaire: results of the BELLA study. Eur Child Adolesc Psychiatry 2008;17(1):125-32.

16. Jafari $P$, Sharafi Z, Bagheri Z, Shalileh S. Measurement equivalence of the KINDL questionnaire across child self-reports and parent proxy-reports: a comparison between item response theory and ordinal logistic regression. Child Psychiatr Hum Dev 2014;45(3):369-76.

17. Ribeiro GD, Bach AG, Faria CM, Anastásia S, Almeida HC. Quality of life of patients with strabismus. Arq Brasil de Oftalmol 2014;77(2):110-3.

18. Angeles-Han ST, Griffin KW, Lehman TJ, Rutledge JR, Lyman S, Nguyen JT, Harrison MJ. The importance of visual function in the quality of life of children with uveitis. J Am Assoc Pediatr Ophthal Strabismus 2010;14(2):163-8.

19. Mojon-Azzi SM, Potnik W, Mojon DS. Opinions of dating agents about strabismic subjects' ability to find a partner. Br J Ophthalmology 2008;92(6):765-9.

20. Archer SM, Musch DC, Wren PA, Guire KE, Del Monte MA. Social and emotional impact of strabismus surgery on quality of life in children. J Am Assoc Pediatr Ophthal Strabismus 2005;9(2):148-51.

21. Kothari M, Balankhe S, Gawade R, Toshnival S. Comparison of psychosocial and emotional consequences of childhood strabismus on the families from rural and urban India. Indian J Ophthal 2009;57(4):285-90.

22. Haney P, Durlak JA. Changing self-esteem in children and adolescents: A meta-analytical review. J Clin Child Psychol 1998;27(4):423-33.

$* * * * * * * * * * * * * * * * * * * * * * * * * * * * * * * * * * * *$

$$
\begin{gathered}
\text { Acknowledgements - Nil } \\
\text { Conflict of Interest - Nil; } \\
\text { Funding - Nil }
\end{gathered}
$$

